\title{
Improving Learning in Rural Lower Primary School through Provision of Informal ECD: Lessons from an NGO Model in Uganda
}

\author{
Betty Akullu Ezati ${ }^{1}$ (iD \\ Aramanzan Madanda ${ }^{2}$ \\ Josephine Ahikire ${ }^{3}$ \\ ${ }^{1,3}$ Makerere University, Uganda \\ Email:bezati@cees.mak.ac.ug Tel: +256772467189 \\ Email:jahikire@chuss.mak.ac.ug Tel: +25675266784t. \\ Researcher, Centre for Basic Research, Uganda \\ ¿Email:amadanda@gmail.com Tel:+256776110126
}

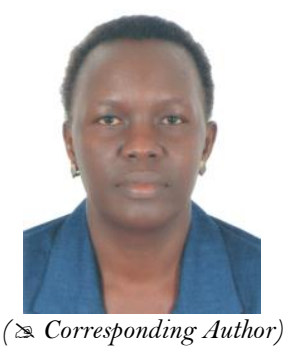

\begin{abstract}
Despite the importance of early childhood education in improving academic achievements in subsequent years and also in social development, it remains out of reach for majority of children in developing countries. This leaves informal education as the main preparation children in rural areas receive before entry into primary schools. This paper focuses on contributions of informal early childhood education to pupils learning in lower primary schools. Data was drawn from a three-year longitudinal study of children who had benefitted from the informal early childhood education provided by a nongovernmental organization (LABE), in Uganda. Findings show that attendance of informal home based learning improves pupils' performance in literacy and numeracy by primary three. Children who attend the informal early childhood education performed better than those who start school direct from home. Informal early childhood education also increases children readiness for schools and helps them cope better with school. The paper recommends adaptation of the LABE model in rural areas with inadequate formal ECCE provisions. In addition, for improved supervision, linking HLC and primary schools is critical.
\end{abstract}

Keywords: Informal early childhood education, Learning, Rural, NGO.

Citation | Betty Akullu Ezati; Aramanzan Madanda; Josephine Ahikire (2018). Improving Learning in Rural Lower Primary School through Provision of Informal ECD: Lessons from an NGO Model in Uganda. Journal of Education and e-Learning Research, 5(1): 51 59 .

History:

Received: 14 November 2017

Revised: 6 February 2018

Accepted: 9 February 2018

Published: 12 February 2018

Licensed: This work is licensed under a Creative Commons

Attribution 3.0 License $($ (c) $)$ E

Publisher:Asian Online Journal Publishing Group
Contribution/Acknowledgement: All authors contributed to the conception and design of the study.

Funding: The fieldwork was financed by Literacy and Adult Basic Education (LABE). Authors are also indebted to many research assistants and respondents.

Competing Interests: The authors declare that they have no conflict of interests.

Transparency: The authors confirm that the manuscript is an honest, accurate, and transparent account of the study was reported; that no vital features of the study have been omitted; and that any discrepancies from the study as planned have been explained.

Ethical: This study follows all ethical practices during writing.

\section{Contents}

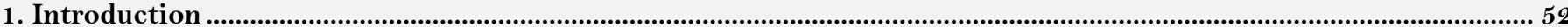

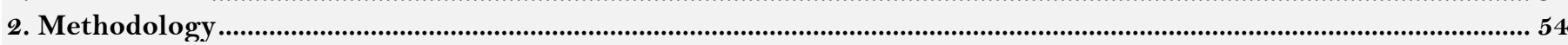

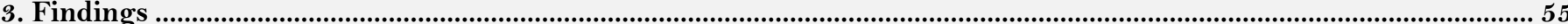

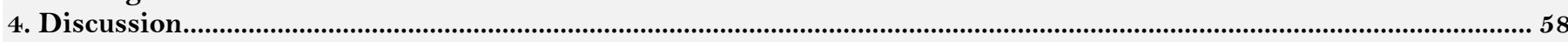

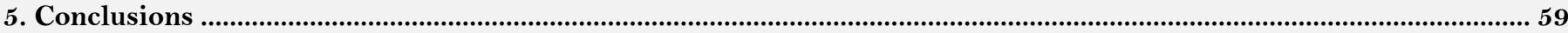

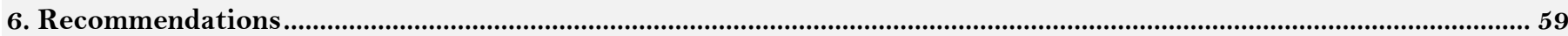

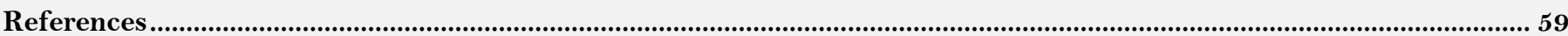




\section{Introduction}

Many scholars agree that Early Childhood Care and Education (ECCE) is important in improving learning and achievement in subsequent levels of education (Strickland and Riley-Ayers, 2006; Burger, 2010; Kwiri, 2013; Patterson et al., 2017). According to Kartal et al. (2016) ECCE plays a vital role in eliminating or minimizing the deficiencies resulting from the socioeconomic structure of the family. For poor children who are less prepared academically due to social and economic factors (Patterson et al., 2017) ECCE reduces inequalities and positively impacts their emotions towards school, teachers and classmates. ECCE shortens the period of adapting to school and to reading-writing expectations and requirements; moreover, schooling is easier and more enjoyable for such children (Kartal et al., 2016). Reynolds et al. (2001) in their longitudinal study found that children who participated in the preschool interventions for 1 or 2 years had a higher rate of high school completion; more years of completed education and lower rates of juvenile arrest. The effects of preschool participation on educational attainment were greater for boys than girls, especially in reducing school dropout rates. Similarly, Martinez et al. (2012) reports that well designed ECCE interventions can result in higher educational attainment and counteract home factors that predict poor performance. Maloney et al. (2015) explain that comprehensive interventions which include extensive family outreach can improve long-term outcomes for children born into lower socio-economic status families. Given its importance, lack of access to ECCE will not only affect the future of the children but that of the country as well.

Magnuson et al. (2007) introduce another aspect to this debate by relating participation in kindergarten education to both cognitive ability and social aspects. In their study, pre-kindergarten is associated with higher reading and mathematics skills at school entry, but also higher levels of behaviour problems. They also report that effects on academic skills largely dissipated by the end of first grade, but the behavioural effects persist. Larger and longer lasting associations with academic gains are found for disadvantaged children. The study also showed that pre-kindergartens located in public schools do not have adverse effects on behaviour problems. These findings suggest that further expansions of pre-kindergarten should focus on serving children from disadvantaged backgrounds and programs located in public schools.

Although there is vast literature on formal ECCE, writing on informal ECCE are just beginning to feature. Lee et al. (1990) compared children without pre-school and those with pre-school experience for disadvantaged children in two American cities in 1969-1970 and found that children who attended pre-school maintained educationally substantive gains in general cognitive and analytic ability compared to children without pre-school experience. In another study, Love et al. (2003) showed that even minimal formal education leads to better learning outcomes than many hours of informal education. In their study, competence scores of children who had attended formal care for fewer hours were higher than those receiving more hours of informal care. Maloney et al. (2015) explained that by the time children begin formal schooling, their experiences at home have already contributed to large variations in their math and language development, and once school begins, academic achievement continues to depend strongly on influences outside of school.

These emerging studies show that informal childhood care and education has minimal impact on performance. Could this apply in a context like Uganda where most children do not access formal ECCE? In addition, views of the different scholars on informal ECCE raise more questions. For instance, in a study by Schafer et al. (2004) on the use of storytelling in development of memory pre-mathematics moral and social skills, language and propagation of culture does not show how story telling should be integrated into ECCE. Moreover, in the study by Schafer et al. (2004) some of the respondents preferred the use of story books while others felt that elderly women should be brought to do the story telling.

The above studies are mainly from developed countries. The few that are from Africa such as Schafer et al. (2004), Pence and Shafer (2006) and from Uganda namely, Gamurorwa (2004) do not examine achievements of children who have been educated through an informal ECCE such as Home Learning Centres, which is the focus of this article.

\subsection{ECD Provision in Uganda}

Uganda is signatory to many international declarations and frameworks on provision of education, including ECD. These include the Dakar Framework of Action, Millennium Development Goals (MDGs), and its successor Sustainable Development Goals (SDGs), Education for All (EFA) goal and the New Partnership for African Development (NEPAD). As a signatory, Uganda committed to attain the goals pertaining to the child with emphasis on expanding and improving comprehensive early childhood care and education especially for the most vulnerable and disadvantaged children (Ministry of Education and Sports, 2007). In addition, Article 34 of the Uganda Constitution commits government and parents to provide a child with basic education. In an effort to fulfill some of the national and international pronouncements, Uganda enacted an ECD policy in 2007 (MoES, 2007) with two main aims: to "develop the child's capabilities, healthy physical growth, good social habits, moral values, imagination, self-reliance, thinking power, appreciation of cultural backgrounds, customs, language and communication skills in the mother tongue"; and to "emphasize the development of a feeling of love and care for other people and Uganda as a whole"(MoES, 2007; NCDC, 2013). The ECD policy 2007 underscores the fact that learning begins at birth and that whatever experience the child goes through in the formative years will impact on the child's learning in later years

Yet, Early Childhood Development (ECD) centres for children 0-6 years largely remain in the hands of the private sector (MoES, 2007) and are concentrated in urban areas due to the prevailing economic, social, geographical, and cultural differences, as well as general beliefs about ECCE. In addition, it is the population in urban centres that can afford the pay fees required by early childhood centers. National Planning Authority (2015) report that over $80 \%$ of the population cannot afford the fees charged for pre-primary education, which limits access. Further, some of ECCE are neither licensed nor registered. There is also inadequate supervision and inspection as most District Inspectors of Schools do not feel it is their mandate to supervise these institutions (MoES, 2007). Until recently (2015), the training of nursery teachers/caregivers was also not streamlined. Many of the training institutions are private owned, with only a few that are affiliated to a public university although it is required by the Ministry of Education and Sports. The training institutions have different entry requirements for 
trainees; follow their own curriculum and certificates offered are not accredited by any recognized body (Ejuu, 2012).

With all these challenges, provision of formal ECCE in Uganda remains low. This pattern of setting up ECCE centres has eliminated majority of the rural children from benefiting in pre-school. The MoES (2007) reported that up to $90 \%$ of the Uganda children aged below 5 were not enrolled in any form of ECCE services. In 2015, the MoES (2015) report puts ECCE enrolment of only 433,258 yet there were over 5 million aged 3-5 years children. In 2015/16 ECCE enrollment increased by a mere The number of pre-primary schools Increased from 5,763 in FY 2015/16 to 6,798 in FY 2016/17; 18 percentage increment. In comparison to other East African countries, Uganda's enrolment in preschools is far behind. In Kenya, enrolment is at 53.5\%; Tanzania at 35.5\% and Rwanda at $29 \%$. Despite the importance of ECCE, the majority of the children in Uganda particularly rural areas do not have access to ECCE. This is compounded by low involvement of parents in early childhood learning because ECCE is not their priority. This could be because many parents are unaware and uncertain of the influence of ECD on the school readiness of their children (Ejuu, 2012).

It is this gap in government provision of ECCE that provided opportunity to individuals, private companies, religious entities, non-governmental organisations and communities to offer early childhood development for children age 0 - 6. One such initiative is Supporting Children's School Readiness and Retention (RARE) project implemented by an NGO known as Literacy and Adult Basic Education (LABE) - Uganda in the eight districts of Gulu, Amuru, Nwoya in Acholi Sub Region and Arua, Yumbe, Koboko, Adjumani and Moyo in the West Nile Sub Region. The project seeks to create literacy-rich home environments in low-income families where many children come from to join primary schools, thus compensating for educational disadvantages such children face at school. In this, home-based learning experiences linked to school activities, support to children's learning is given wherever they are, so as to ease home-primary school transition and ensure that children stay and succeed in school.

\subsection{The LABE RARE Project}

The LABE RARE project is based on a theory of change which recognises that good parenting is crucial to more inclusive education, especially in a society where one generation has lost out on these opportunities due to decades of prolonged conflict, if the cycle of low achievement is to be broken. Hence LABE focused on Early Childhood Care and Education (ECCE) and FABE (Family and Basic Education) in order to improve children's school readiness and retention resulting in affording more pupils the opportunities to access education. The key tenet in the LABE theory of change for the RARE Project is that participation of key groups (parents, educators, government, etc) would bring about systemic change in schools and homes. This in turn would improve children's school readiness, children's transition from home to school retention and increased parental commitment to children's education. In a nutshell, ready homes would create ready children. The theory of change pushes for strengthening educational provisions and information exchange between homes and schools. Figure 1 below is an illustration of the LABE RARE project theory of change.

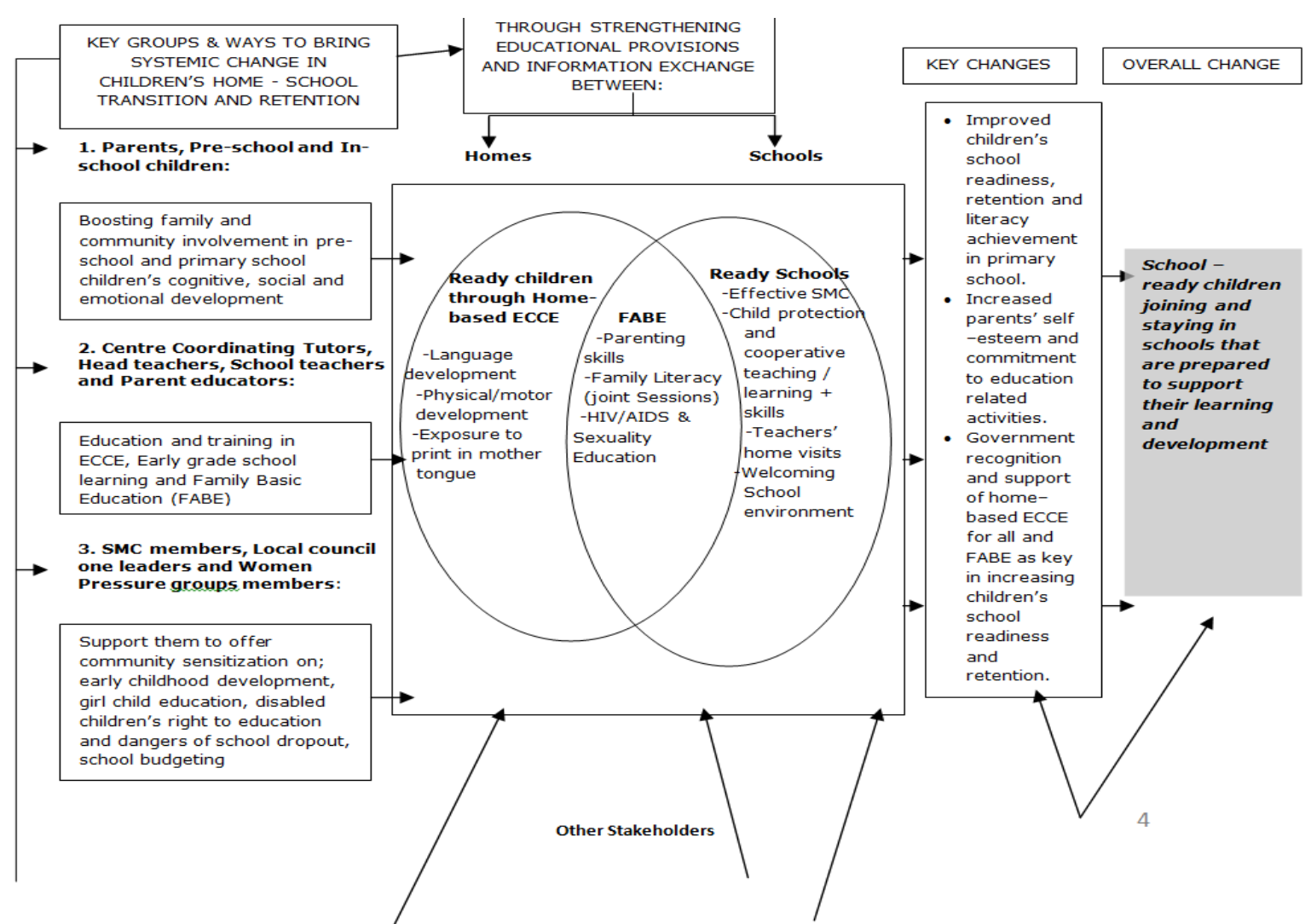

4. Sub county councils and District Education Committees, NCDC, Parliament Social Sector Committee, MOES \& MGLSD:

Advocacy and influencing changes in implementing government policy on ECD and FABE 
The LABE model entails establishing Home Learning Centres (HLCs) in communities. HLCs are community based education centres, many without formal structures by the time of research. But the community selects one home, which provides shelter for children' learning. The homestead is then equipped with basic play facilities such as swings, balls and ropes for skipping, all made from local materials. The teachers called Parent Educators (PEs) are volunteers from the community. Their educational level ranged from primary school leavers to lower secondary schools. School programmes are flexible in terms of days and hours.

The article presents findings on the effects of HLC on children's readiness, retention, and educational achievement in terms of literacy, numeracy and other learning outcomes by primary three.

\subsection{Research Problem}

The link between provision of formal ECCE, children's increased school readiness and improved educational achievement is clear in literature. However, similar research especially in Uganda on informal or home based learning is scanty. Particularly what difference did it make if a child went through an informal pre-school education arrangement in terms of school readiness, retention, literacy or numeracy among others? It was critical to investigate the schooling achievements and drop-out rates amongst children who passed through informal preschools and those who had not had any pre-school preparation as this was critical to inform not only theory but also policy and practice.

As such the purpose of the research was to assess the contribution of informal ECD to primary school readiness of children in rural communities. The research was to generate evidence on whether informal pre-school has an impact on the children's learning achievement in primary school level, in this case until primary three. Specifically, the research answered the following questions:

i. What are the differences in school readiness among children who have attended HLC (informal ECD) and those who have not?

ii. How do the learning outcomes of children who have gone through informal home-based HLC education differ by P.3?

\section{Methodology}

\subsection{Design and Sampling}

This article is based on a longitudinal three-year tracer study spanning from 2014 to 2017. The study utilised a mixed-methods research approach involving the use of quantitative and qualitative approaches. The research was conducted in 16 randomly selected out of the 32 RARE project sub-counties in six out of the eight districts where LABE is supporting HLC. The selected districts were Amuru and Gulu (in Acholi sub-region) and Adjumani, Arua, Koboko and Yumbe (in the West Nile sub-region). The districts that had a higher number of sub-counties had more of them selected for the study.

Table-1.Sample size and composition

\begin{tabular}{|c|c|c|c|c|c|c|c|c|c|c|}
\hline $\begin{array}{l}\text { Sub } \\
\text { region }\end{array}$ & District & $\begin{array}{l}\text { Sub- } \\
\text { County }\end{array}$ & Sch. & $\begin{array}{l}\text { Head } \\
\text { Teacher }\end{array}$ & $\begin{array}{l}\text { P1. } \\
\text { Class } \\
\text { teacher }\end{array}$ & $\begin{array}{l}\text { Pupils } \\
\text { Expt.(P.1) }\end{array}$ & $\begin{array}{l}\text { Pupils } \\
\text { control } \\
\text { (P.1) }\end{array}$ & Parents & $\begin{array}{l}\text { Parent } \\
\text { Educators }\end{array}$ & $\begin{array}{l}\text { District } \\
\text { officials }\end{array}$ \\
\hline \multirow{13}{*}{$\begin{array}{l}\underset{8}{8} \\
\stackrel{2}{+} \\
\underset{2}{2}\end{array}$} & \multirow[t]{4}{*}{ Adjumani } & Adropi & 1 & 1 & 1 & \multirow[t]{4}{*}{56} & \multirow[t]{4}{*}{56} & \multirow[t]{4}{*}{112} & \multirow[t]{4}{*}{6} & \multirow[t]{4}{*}{3} \\
\hline & & Dzaipi & 1 & 1 & 1 & & & & & \\
\hline & & Pacara & 2 & 2 & 2 & & & & & \\
\hline & & Pakele & 1 & 1 & 1 & & & & & \\
\hline & \multirow[t]{4}{*}{ Arua } & Adumi & 1 & 1 & 1 & \multirow[t]{4}{*}{72} & \multirow[t]{4}{*}{72} & \multirow[t]{4}{*}{144} & \multirow[t]{4}{*}{8} & \multirow[t]{4}{*}{4} \\
\hline & & Pajulu & 1 & 1 & 1 & & & & & \\
\hline & & Ajia & 1 & 1 & 1 & & & & & \\
\hline & & Oluko & 1 & 1 & 1 & & & & & \\
\hline & Koboko & Kuluba & 6 & 6 & 6 & 53 & 53 & 106 & 8 & 3 \\
\hline & \multirow[t]{4}{*}{ Yumbe } & Odravu & 1 & 1 & 1 & \multirow[t]{4}{*}{87} & \multirow[t]{4}{*}{87} & \multirow[t]{4}{*}{174} & \multirow[t]{4}{*}{3} & \multirow[t]{4}{*}{3} \\
\hline & & Apo & 2 & 2 & 2 & & & & & \\
\hline & & Kululu & 1 & 1 & 1 & & & & & \\
\hline & & Lodonga & 1 & 1 & 1 & & & & & \\
\hline \multirow{4}{*}{$\begin{array}{l}\frac{3}{0} \\
\stackrel{0}{0} \\
\stackrel{0}{0} .\end{array}$} & \multirow[t]{2}{*}{ Amuru } & Atiak & 1 & 1 & 1 & \multirow[t]{2}{*}{52} & \multirow[t]{2}{*}{52} & \multirow[t]{2}{*}{104} & \multirow[t]{2}{*}{12} & \multirow[t]{2}{*}{3} \\
\hline & & Paboo & 5 & 5 & 5 & & & & & \\
\hline & Gulu & Awach & 3 & 3 & 3 & 38 & 38 & 76 & 3 & 3 \\
\hline & Total & & 29 & 29 & 29 & 358 & 358 & 716 & 40 & 19 \\
\hline
\end{tabular}

Of the 120 "RARE schools", 29 were selected using simple random sampling. Again, sub-counties with more participating schools had more schools selected than those with fewer schools. During the first year/episode of fieldwork, a list of children in primary one was obtained from the class teacher of each school. The list was split into children who went through the RARE HLC and those who did not have any pre-school education. Pupils who went through any other ECD training (not under the RARE project) were excluded from the study. A 30 percent sample was drawn randomly from each group. The RARE project beneficiaries constituted the treatment group; while the second set of children were the control group.

From the selected children, parents were traced for consent to their children's enrolment in the study as well as for recruitment into the tracer study as participants. Previous Home Learning Centres for the children in the treatment group were also traced and the Parent Educators enlisted as key informants. The Primary 1, 2 and 3 Class Teachers, head teachers and district officials were also included as key informants.

The size and composition of the interviewees is as presented in Table 1.

As seen from the Table 1, 19 district leaders participated in the study. These included: the District Education Officers (DEO); District Inspectors of Schools (DIS); and the Local Council Five (LCV) Secretaries for Education. 
A total of 716 pupils (358 for the experimental group and 358 control group and their parents/guardians were drawn for the study. Table 2 below shows the actual number of children that participated in the study for episode 1 (year 1), episode two (Year 2) and episode three (year 3).

Table-2.Children that participated in the Study over the three years by district and sex

\begin{tabular}{|c|c|c|c|c|c|c|c|c|c|c|c|c|c|c|c|c|c|c|}
\hline \multirow{4}{*}{$\begin{array}{l}\text { District } \\
\text { Name }\end{array}$} & \multicolumn{6}{|c|}{ Episode 1} & \multicolumn{6}{|c|}{ Episode 2} & \multicolumn{6}{|c|}{ Episode 3} \\
\hline & \multicolumn{4}{|c|}{ Sex of child } & \multirow{2}{*}{\multicolumn{2}{|c|}{ Total }} & \multicolumn{4}{|c|}{ Sex of Child } & \multirow{2}{*}{\multicolumn{2}{|c|}{ Total }} & \multicolumn{4}{|c|}{ Sex of Child } & \multirow{2}{*}{\multicolumn{2}{|c|}{ Total }} \\
\hline & \multicolumn{2}{|c|}{ Male } & \multicolumn{2}{|c|}{ Female } & & & \multicolumn{2}{|c|}{ Male } & \multicolumn{2}{|c|}{ Female } & & & \multicolumn{2}{|c|}{ Male } & \multicolumn{2}{|c|}{ Female } & & \\
\hline & No & $\%$ & No & $\%$ & No & $\%$ & No & $\%$ & No & $\%$ & No & $\%$ & No & $\%$ & No & $\%$ & No & $\%$ \\
\hline Adjumani & 44 & 12.9 & 53 & 14.4 & 97 & 13.7 & 31 & 12.0 & 40 & 14.0 & 71 & 13.0 & 32 & 14.8 & 36 & 14.9 & 68 & 14.8 \\
\hline Arua & 78 & 22.8 & 84 & 22.9 & 162 & 22.8 & 58 & 22.4 & 52 & 18.2 & 110 & 20.2 & 57 & 26.4 & 52 & 21.5 & 109 & 23.8 \\
\hline Koboko & 58 & 17.0 & 57 & 15.5 & 115 & 16.2 & 36 & 13.9 & 39 & 13.6 & 75 & 13.8 & 25 & 11.6 & 30 & 12.4 & 55 & 12.0 \\
\hline Yumbe & 75 & 21.9 & 78 & 21.3 & 153 & 21.6 & 72 & 27.8 & 76 & 26.6 & 148 & 27.2 & 50 & 23.1 & 58 & 24.0 & 108 & 23.6 \\
\hline Amuru & 52 & 15.2 & 53 & 14.4 & 105 & 14.8 & 43 & 16.6 & 46 & 16.1 & 89 & 16.3 & 29 & 13.4 & 41 & 16.9 & 70 & 15.3 \\
\hline Gulu & 35 & 10.2 & 42 & 11.4 & 77 & 10.9 & 19 & 7.3 & 33 & 11.5 & 52 & 9.5 & 23 & 10.6 & 25 & 10.3 & 48 & 10.5 \\
\hline Total & 342 & 100 & 367 & 100 & 709 & 100 & 259 & 100 & 286 & 100 & 545 & 100 & 216 & 100 & 242 & 100 & 458 & 100 \\
\hline
\end{tabular}

In total, 709 (out of the initially selected 716) children from six districts took part in the first episode (year 1) of the study, of which $342(48.2 \%)$ were male and $367(51.8 \%)$ were female. In the second episode/year 2 , the children that participated in the study dropped to 545 consisting of 259 males $(47.5 \%)$ and $286(52.5 \%)$ females. In the third episode the children dropped further to 458 consisting of 216 males $(47.2 \%)$ and 242 females (52.8\%). Overall, there was a $23 \%$ of all children selected that dropped out of the study from the first to the second episode, while $15 \%$ of all children that took part in the second episode also dropped out by the third episode. Essentially, there were a bigger percentage of boys that dropped out of the study between the first and the third episode, from the overall participation of $48.2 \%$ to $47.2 \%$ while the overall percentage of girls rose from $51.8 \%$ in the first episode to $52.8 \%$ during the third episode. It is not clear why proportionately more boys dropped out of the study than girls did. However, in general, the reasons for the dropout/reduction in participation of children in the tracer study are varied ranging from the fact that some had dropped out of school, others had moved away from the districts of study or it was due to non-traceability.

All the 709 children interviewed in the first field episode were in primary 1. The average age of the children interviewed during the first episode/first year of the study was 8 years, which is higher than the national average, where children in primary one average six years, indicating that children in the study areas go to primary school a bit later. However as can be seen from the following Table 3, progression of children is problematic and some of the children identified in primary 1 in the first episode were still in the same class three years later.

\subsection{Data Collection Methods and Tools}

Data was collected from key informant interview (KII) guides, Focus Group discussions and a structured interview using a questionnaire. Most of the items in the questionnaires were close-ended, which allowed for easier analysis, tabulation and comparison across the years as well as standardized reporting.

\subsection{The Research Process}

Data was collected from both the treatment/experimental and the control groups of children. The treatment group was made up of children that had prior education in the HLC before joining primary 1 while the control group started their formal schooling in primary 1 . The children initially selected included an equal number of boys and girls. The researchers collected details of the children and their family characteristics including name (for follow up purposes), age, sex, class, religion, disability, occupation, mother's and fathers' level of education, language commonly used at home or school and number of months in the RARE project programme. The children and parents who participated in Phase 1 formed the cohort of children and families that were traced and followed up for the rest of the study period and field episodes till 2017.

\subsection{Data Analysis}

Data capture and coding was executed in accordance with the structured format in the questionnaires. Hence most of the data was cast in frequencies from which percentages were computed and analysed using the SPSS computer programme. Cross tabulations and controlling for relationships of interest were conducted on the data to reveal more intricate relationships and aspects. Qualitative data was analysed manually on the basis of relevant themes. This report is written out of triangulated data and information from the field and written sources.

\section{Findings}

\subsection{Difference in School Readiness among Children Who Have Attended Informal ECD (HLC)} and Those Who Have Not

Results show significant variation in learning outcomes of children that went through the HLC with those that simply started their education in primary one straight from their homes. According to the teachers, children who have been to HLC were more disciplined and socialised better. These findings are shown in Figure 2. 


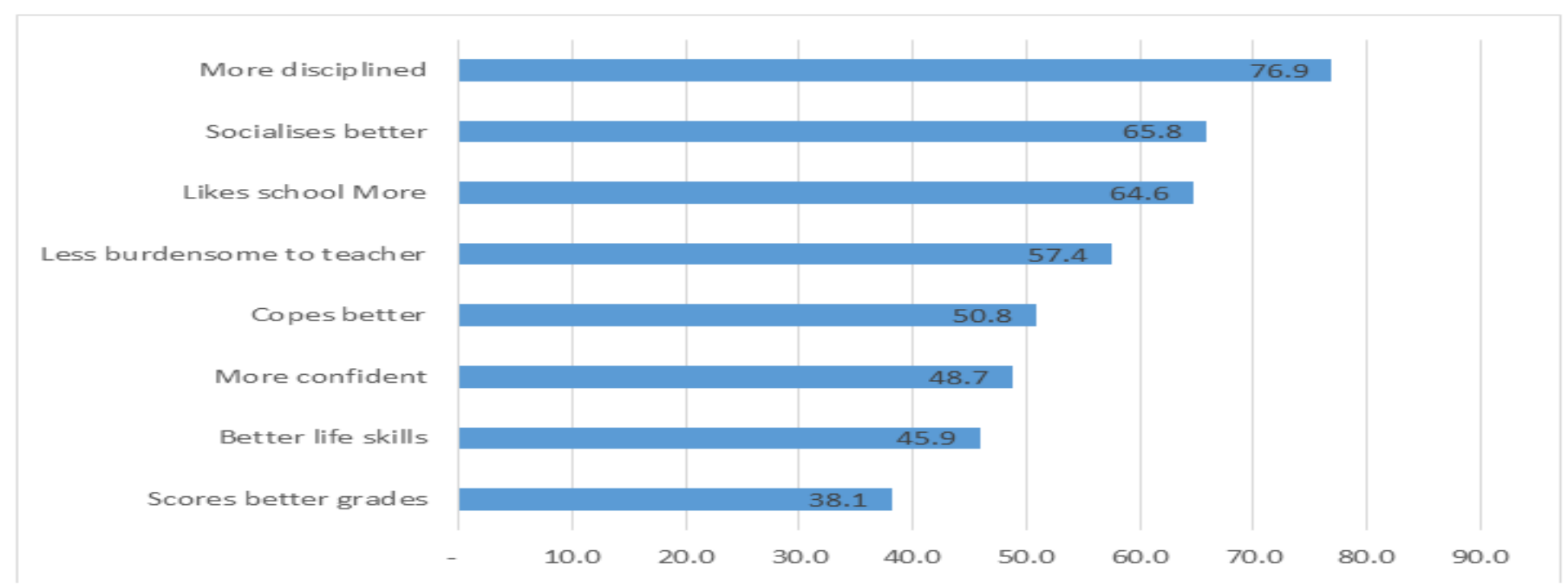

Figure-2. Teachers' responses on the school readiness of children who attended HLC

From Figure 2 above, a majority of the teachers interviewed over the three years agree and strongly agree that children who went through HLCs compared to others are: more disciplined (76.9\%), socialised better at school $(65.8 \%)$, liked school more $(64.6 \%)$, were less burdensome to the teacher $(57.4 \%)$ and coped better with formal school life $(50.8 \%)$. However, fewer teachers agreed or strongly agreed to the points that: they are more confident $(48.7 \%)$, they had better life-skills $(45.9 \%)$ or scored better grades $(38.1 \%)$.

On coping with formal schooling better, qualitative responses from the teachers and head teachers showed that the HLC prepares children better for primary schooling. This is because the children move to primary level when they have basic knowledge of how the schools function and what is expected of school going children. As one of the head teachers explained, "They respond to calls, they are used to teachers unlike children who come direct from the villages that run away when called. Socializing is easy compared to those from home, who cannot socialize. They talk freely compared to those who have not been to school.The HLC children come when they have learnt sanitary habits." Similarly, one of the teachers explained that, "they associate with others, share with others, teaching them writing is not difficult. They are also committed and responsible."

While findings from the teachers ranked "disciplined", "socialises better" and "likes school better" as the qualities children who have been to HLC exhibited, the parents' responses had "copes better with school" and "likes school" as the top two with a third being those who did not see any difference among the two categories. These variations in response could be due the fact that teachers interacted with wider array of both categories of children while parents either had those who had gone to HLC or not. Views of parents about advantages of children who have gone through HLCs are presented in the following Figure 3.

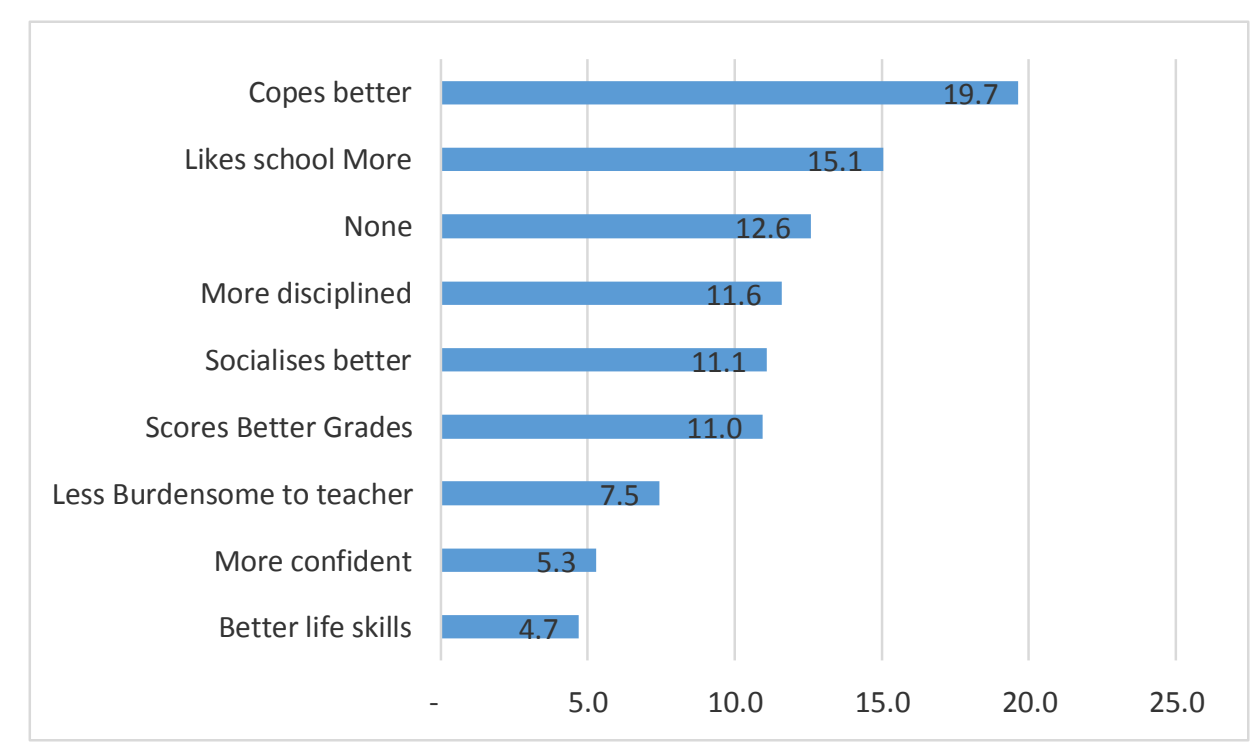

Figure-3.Parents' views (\%) on advantages for Children who go through the HLC Source: From the Authors' field data.

While citing advantages, the parents were more conservative in terms of the advantages enjoyed by children that had gone through the HLCs ranging from $4.7 \%$ of the responses representing those with better life skills to $19.7 \%$ representing children who cope better with formal schooling. In between, parents' responses showed the following advantages of children who had gone through HLCs: they liked school more (15.1\%), they were more disciplined $(11.6 \%)$, they socialised better $(11.1 \%)$ and that such children were less burdensome to teachers $(7.5 \%)$ or were more confident $(5.3 \%)$. However, $12.6 \%$ of the responses of parents named no comparative advantage enjoyed by those that went through HLCs. This could be attributed to the absence of such HLCs in their villages.

\subsection{What Children Liked Most about School}

Since both parents and teachers reported that children who went through HLC liked school more than those that started schooling from primary one, the children were further asked what they liked most about their schools. A multiple response analysis to an open-ended question: what do you like most about school, showed that children liked the school environment, playing, singing and learning. These are shown in Figure 4. 


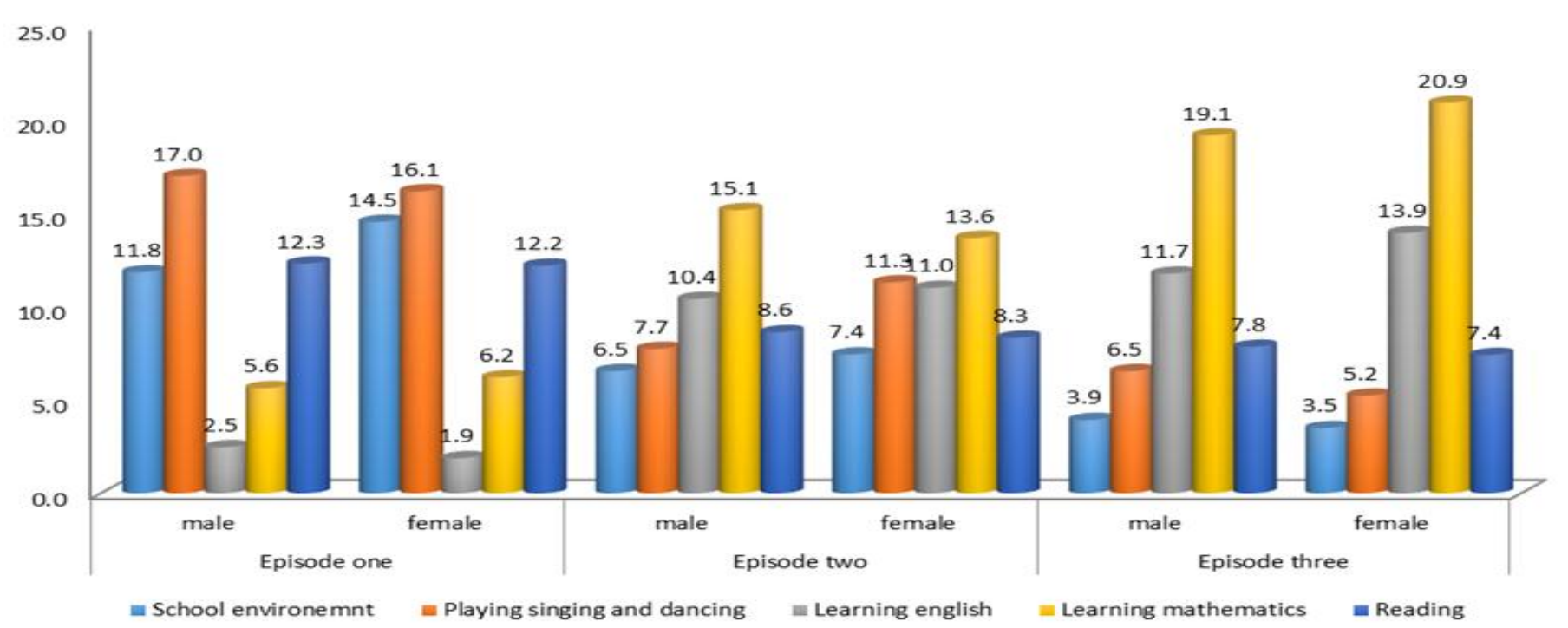

Source: From the Authors' field data.

Figure-4. What Children liked most about School (\%)

When responses from girls and boys are compared, girls liked more the school environment and learning English language, while more boys enjoyed playing including singing and dancing as well as learning mathematics. Other aspects liked by the children were writing, teachers and reading. See Figure 4 for variations across the years.

\subsection{Subjects that Children Enjoyed Most}

Survey results indicate that close to $90 \%$ of boys and girls reported that they enjoyed learning Mathematics, Literacy, Physical Education, Art and Music. However, about 30\% of the children said they did not enjoy learning the English language, yet it is the language used by some schools for instruction. This is against the Ministry of Education and Sports policy that encourages the use of the local languages in teaching the thematic curriculum. This deviation from policy could be partly because of the language mix of children in some districts that made it difficult to zero on one common local language for instruction. Given that, relatively fewer children said they enjoyed learning the English language (See Table 3), the general understanding of all the subjects is likely to be affected in the schools that use it for instruction. Children's likes and dislikes translate into performance.

Table-3.Subjects children described as their most liked and most difficult by Sex

\begin{tabular}{|c|c|c|c|c|c|c|c|c|}
\hline \multirow[t]{3}{*}{ Subject } & \multicolumn{4}{|c|}{ Most liked subject } & \multicolumn{4}{|c|}{ Most difficult subject } \\
\hline & \multicolumn{2}{|c|}{ Control } & \multicolumn{2}{|c|}{ Experiment } & \multicolumn{2}{|c|}{ Control } & \multicolumn{2}{|c|}{ Experiment } \\
\hline & $\begin{array}{l}\text { Male } \\
(\%)\end{array}$ & $\begin{array}{l}\text { Female } \\
(\%)\end{array}$ & $\begin{array}{l}\text { Male } \\
(\%)\end{array}$ & $\begin{array}{l}\text { Female } \\
(\%)\end{array}$ & $\begin{array}{l}\text { Male } \\
(\%)\end{array}$ & $\begin{array}{l}\text { Female } \\
(\%)\end{array}$ & Male (\%) & $\begin{array}{l}\text { Female } \\
(\%)\end{array}$ \\
\hline Mathematics & 45.2 & 46.8 & 47.6 & 37.9 & 18.5 & 23.7 & 17.1 & 24.6 \\
\hline English & 15.8 & 14.1 & 14.9 & 18.8 & 42.7 & 45.3 & 45.8 & 41.2 \\
\hline Artandcraft & 7.3 & 5.8 & 4.8 & 7.2 & 7.9 & 5.3 & 4.9 & 5.4 \\
\hline Writing & 12.9 & 13.1 & 11.0 & 12.3 & 5.7 & 4.1 & 6.1 & 6.1 \\
\hline Reading & 7.9 & 10.3 & 10.0 & 10.6 & 11.0 & 8.2 & 11.6 & 8.4 \\
\hline MusicandPE & 4.6 & 5.1 & 5.8 & 8.3 & 2.6 & 1.6 & 2.9 & 2.6 \\
\hline Other & 6.3 & 4.8 & 5.8 & 4.9 & 11.5 & 11.8 & 11.6 & 11.8 \\
\hline Total & 100 & 100 & 100 & 100 & 100 & 100 & 100 & 100 \\
\hline
\end{tabular}

Source: Computed from data collected by the Authors.

From the above table, the highest proportion of female and male children both among the experimental and control groups indicated mathematics as their most-liked subject while English language was reported as the most difficult. Most children said mathematics was easy to understand and interesting, which is why it was their best subject. However, while the difference between boys who liked mathematics is small between the control group $(45.2 \%)$ and the experimental $(47.6 \%)$, the gap is higher for girls where for the control group $46.8 \%$ reported liking mathematics compared to $37.9 \%$ of girls who liked mathematics in the experimental group.

As for those who found English more difficult, the majority of the boys were in the experimental group while the majority of the girls were in the control group. These findings point to a very complex relationship between attending a HLC and how children's dislikes of particular subjects. Dislike for English language could be a result of the fact that most instruction at this level is in indigenous languages except for a few children. Two major reasons identified by the children for "hard" subjects were that the subject was difficult (51\%) or was not easy to understand $(16.3 \%)$. This is worrying as later learning outcomes are examined in the English language which the children as early as primary one to primary three found difficult to comprehend.

\subsection{Comparison of Learning Outcomes of Children Who Have Gone Through Informal Home- Based HLC Education and Those Who Have Not}

One of the main questions was on the difference that Home Learning Centres make. Results from standard tests on numeracy and literacy indicated that children who went through the HLC scored relatively better in numeracy and literacy, by a range of about $8.9 \%$ and $8.3 \%$ respectively, by primary three. The results are presented in Table 4 
Table-4. Results of Standard Literacy and Numeracy Tests for selected children by Primary 3

\begin{tabular}{l|l|l|l|l|l|l|l}
\hline & & Control & Experimental & \multicolumn{2}{l}{ Total } \\
\cline { 3 - 9 } & & No & $\mathbf{9}$ & No & \% & No & \% \\
\hline \multirow{2}{*}{ Literacy } & Inadequate & 57 & 65.5 & 64 & 58.2 & 121 & 61.4 \\
\cline { 2 - 9 } & Proficient & 30 & 34.5 & 46 & 41.8 & 76 & 38.6 \\
\cline { 2 - 9 } & Total & $\mathbf{8 7}$ & $\mathbf{1 0 0 . 0}$ & $\mathbf{1 1 0}$ & $\mathbf{1 0 0 . 0}$ & $\mathbf{1 9 7}$ & $\mathbf{1 0 0 . 0}$ \\
\hline \multirow{2}{*}{ Numeracy } & Inadequate & 52 & 59.8 & 56 & 50.9 & 108 & 54.8 \\
\cline { 2 - 9 } & Proficient & 35 & 40.2 & 54 & 49.1 & 89 & 45.2 \\
\cline { 2 - 9 } & Total & $\mathbf{8 7}$ & $\mathbf{1 0 0 . 0}$ & $\mathbf{1 1 0}$ & $\mathbf{1 0 0 . 0}$ & $\mathbf{1 9 7}$ & $\mathbf{1 0 0 . 0}$ \\
\hline
\end{tabular}

Source: Computed from NAPE ${ }^{1}$ Standard Tests Records, 2017

From Table 5 below, the following can be noted: the pupils that went through the HLC performed relatively better i.e. were more proficient in literacy at $41.8 \%$ of the children that attempted the standard test as compared to $34.5 \%$ for the control group giving a range (difference) of 8.3 percentage points. As for numeracy, the experimental group still performed better and was more proficient at $49.1 \%$ of those subjected to the standard test as compared to $40.2 \%$ of the control group giving a range (difference) of 8.9 percentage points. It is clear therefore, that if all children had gone through the HLC programme, performance in literacy and numeracy would have been higher by about 8 percent in literacy and about 9 percent in numeracy other factors held constant. However, given that the experimental group that scored at proficiency level of less than half in both literacy $(41.8 \%)$ and numeracy $(49.1 \%)$ means that a lot more needs to be done in terms of what the HLCs provided. There is need to address other contributing factors, which are necessary to ensure that the majority of children score higher grades. As noted earlier, a range of inputs are necessary to get better results in addition to the effect of the HLC such as provision of adequate scholastic materials and strengthening parental involvement.

Although attendance of HLC improved performance in primary schools, progression remains poor as shown in Table 3 .

Table-5. Progressions of children from Primary 1 to 3 during the study period

\begin{tabular}{|c|c|c|c|c|c|c|c|c|c|c|c|c|}
\hline \multicolumn{5}{|c|}{ Episode 1/First Year } & \multicolumn{4}{|c|}{ Episode 2/Second Year } & \multicolumn{4}{|c|}{ Episode 3/Third Year } \\
\hline Class & Male & Female & Total & $\%$ Female & Male & Female & Total & $\%$ Female & Male & Female & Total & $\%$ Female \\
\hline Primary 1 & 342 & 367 & 709 & 51.8 & 78 & 97 & 175 & 55.4 & 24 & 21 & 45 & 46.7 \\
\hline Primary 2 & - & - & - & - & 177 & 180 & 357 & 50.4 & 67 & 76 & 143 & 53.1 \\
\hline Primary 3 & - & - & - & - & 1 & 4 & 5 & 80.0 & 121 & 138 & 259 & 53.2 \\
\hline
\end{tabular}

Source: Computed from the Authors' field data.

Table 3 above shows that, in the second year of the tracer study, while all children were expected to be in primary 2, 175 of which $55.4 \%$ were female were still in primary 1. Curiously, 5 children were already in primary 3 , 4 of which $(80 \%)$ were female. During the third year of the study, where all children identified in year 1 were expected to be in primary 3, 45 of which $46.7 \%$ are female were still in primary 1 , while 143 of which $53.1 \%$ were female were still in primary two. The factors for repetition are varied. While some children may not progress due to academic background, some enrolled too young and cannot be able to progress.

Findings from the teachers also confirmed the results of the standard tests. There are variations in learning outcomes of children that went through the HLC compared to those that simply started their education in primary one straight from their homes. According to the respondents, those from the HLC learn faster because they already have the experience of what it takes to be at school. As one of the primary one teacher explained, "They can recognize letters, count numbers 1-100. They can respond to questions with confidence, do not fear anymore.TheHLC helps to produce good children who are easy to teach and this improves transition from home to school." Another teacher also explained: "children who have been to the HLC get acquainted to the learning situation early enough such that by the time they go to primary school, teaching and learning is easier as compared to those who come directly from homes". HLC provides a foundation for education and a base for teachers to begin work. It therefore lessens the work of the teacher according to the respondents.

\section{Discussion}

One of the critical assumptions that the study tested was that children's increased school readiness and retention leads to improved educational achievement in terms of literacy, numeracy and other learning outcomes. The LABE RARE project theory of change advances key assumptions some of which are that: participation of key groups in ways that bring about systemic change in schools and homes aids children's transition from home to school and retention. Once these are in place the noted results as espoused by the theory of change are improved children's school readiness, increased parental commitment to children's education and government recognition and support. The overall change is envisaged to be school ready children who join and stay in school.

The tracer research rigorously tested these theoretical assumptions among other aspects for possible generalisation and replication. By focusing on early childhood care and education and family as articulated in the project theory of change the LABE RARE project successfully and significantly improved school readiness for a majority of children involved. The children who have gone through HLC performed better, successfully progressed through the classes, liked schools and the different subjects more than those without any experience of pre-school. This confirms studies by Patterson et al. (2017); Kwiri (2013); Burger (2010); Strickland and Riley-Ayers (2006) that ECD improves learning and achievement, even when these studies were all in formal settings. It also improves retention and the children easily adapt to school. This was also reported by Kartal et al. (2016). For rural schools with inadequate provision for ECD, the LABE model provides hope for the children. 


\section{Conclusions}

In conclusion this study confirmed that attendance of informal home based learning improves pupils' performance in literacy and numeracy by primary three. Attendance of a HLC helped children across the board to cope better with school. Such children also liked school and scored higher grades in general as compared to the rest that did not go through a similar background. Increased child readiness and therefore interest in school activities improves attendance, participation in school activities and educational achievements.

The findings also showed that overall, most of the children whether in the control or experimental group did not achieve the level of proficiency in numeracy and literacy. This implies that the intervention though important was not sufficient to push the majority of children to proficiency levels in both numeracy and literacy.

\section{Recommendations}

Given the findings, discussion and the above conclusions, the following are some of the key recommendations:

1. Advocate for introduction of the LABE informal HLC in areas without formal ECCE. For a start LABE should package and disseminate results of this study to the various targeted groups. An effective advocacy programme is needed to heighten the awareness of policy makers at district and sub county levels, to further expand, strengthen and create a more favourable institutional environment for promoting HLCs in the rural areas.

2. Expand Focus to Include "Ready Primary Schools for Ready Children and Ready Homes." To promote retention, LABE should explore a community supported partnership model with primary schools to make them as interesting and attractive to children that go through HLCs. Primary schools which had no playing kits and meals for children were found less attractive to some children that had already been exposed to such benefits in the LABE HLCs. Partnership with already funded primary schools in terms of staff remuneration may make the interventions more sustainable. LABE should initiate or strengthen collaboration between HLCs and nearby primary schools for supervisory support.

3. Create awareness of the LABE model: There is need to have a rigorous process of creating awareness among national institutions such as: the ministry of gender, labour and social development, the ministry of education and sports, the parliamentary committees on gender and education and the local government councils for further support to early learning, parental involvement and favourable policies and legislation.

4. Build in a strong national advocacy element in ECD interventions: Creation of a new environment in which parents recognise the importance of the HLCs would require numerous measures. Foremost among these should be a need for LABE to have a communication strategy that promotes an active awareness raising campaign in the mass media and through religious institutions, as well as awareness drives through community-based activities such as meetings, target group discussions and distribution of brochures and leaflets. The LABE ECD model should be clearly documented and form part of the massive awareness and advocacy campaigns.

\section{References}

Burger, K., 2010. How does early childhood care and education affect cognitive development? Early Childhood Research Quarterly, 25(2): 140-165. View at Google Scholar View at Publisher

Ejuu, G., 2012. The status of implementation of the education sector early childhood development policy in Uganda. A Report Submitted to UNESCO.

Gamurorwa, A., 2004. Utilizing indigenous stories in the promotion of early childhood development programs in Uganda. Unpublished Master's Major Project Report, University of Victoria, Victoria, British Columbia, Canada.

Kartal, H., Y. Balantekin and A. Bilgin, 2016. The importance of early childhood education and school starting age in the reading-writing learning process. Participatory Educational Research, 3(1): 79-101. View at Google Scholar $\mid$ View at Publisher

Kwiri, K.T., 2013. Supporting children's school readiness and retention (RARE) Project baseline survey: Analysis Report. LABE: Kampala.

Lee, V.E., J. Brooks-Gunn, E. Schnur and L. Fong-Ruey, 1990. Are head start effects sustained/ a longitudinal follow- up comparison of disadvantaged children attending head start. No Preschool and Other Preschool Programs Child Development, $61(2)$ : 495 - 507. View at Google Scholar | View at Publisher

Love, J.M., L. Harrison, A. Sagi-Schwartz, M.H. Van IJzendoorn, C. Ross, J.A. Ungerer, H. Raikes, C. Brady-Smith, K. Boller, J. BrooksGunn, J. Constantine, E.E. Kisker, D. Paulsell and R. Chazan-Cohen, 2003. Child care quality matters: How conclusions may vary with context. Child Development, 74(4): 1021-1033. View at Google Scholar | View at Publisher

Magnuson, K.A., C. Ruhm and J. Waldfogel, 2007. Does prekindergarten improve school preparation and performance? Economics of Education Review, 26(1): $33-51$. View at Google Scholar | View at Publisher

Maloney, A.E., A.B. Converse, R.C. Gibbs, C.L. Susan and B.L. Sian, 2015. Jump-starting early childhood education at home: Early learning, parent motivation, and public policy. Perspectives on Psychological Science, 10(6): 727-732. View at Google Scholar | View at Publisher

Martinez, S., S. Naudeau and V. Pereira, 2012. The promise of preschool in Africa: A Randomized Impact Evaluation of Early Childhood Development in Rural Mozambique IDB World Bank PUC-Rio A World Bank Report.

Ministry of Education and Sports, 2007. The early childhood development (ECD). Policy: Kampala

MoES, 2015. The Education and Sports Sector Annual Performce Report, Kampala.

National Planning Authority, 2015. Pre-primary and Primary Education in Uganda: Access, Cost, Quality and Relevance, Kampala.

NCDC, 2013. Caregivers' guide to the learning framework for early childhood development 3 - 6 years. Kampala.

Patterson, G.C., Y.L. Dunston and K.N. Daniels, 2017. HBCUs to the rescue: Utilizing service-learning pedagogy to improve teacher preparation in early childhood education. In: Heider K. (Eds) Service Learning as Pedagogy in Early Childhood Education. Educating the Young Child (Advances in Theory and Research, Implications for Practice). Springer, Cham, 11.

Pence, A. and J. Shafer, 2006. Indigenous knowledge and early childhood development in Africa: The early childhood development virtual university. Journal for Education in International Development, 3(3): 1-16. View at Google Scholar

Reynolds, A.J., J.A. Temple, D.L. Robertson and E.A. Mann, 2001. Long-term effects of an early childhood intervention on educational achievement and juvenile arrest a 15-year follow-up of low-income children in public schools. American Journal of Medical Association, 285(8): 2339-2346. View at Google Scholar | View at Publisher

Schafer, J., M. Ezirim, A. Gamurorwa, P. Ntsonyane, M. Phiri and J. Saignia, 2004. Exploring and promoting the value of indigenous knowledge in early childhood education development in Africa. International Journal of Educational Policy, Research and Practice: Reconceptualizing Childhood Studies, 5(3): 61-80. View at Google Scholar

Strickland, D. and S. Riley-Ayers, 2006. Early literacy: Policy and practice in the preschool. Preschool Policy Brief, 10: 1-12. View at Google Scholar 